\title{
Effect of hydrolysed egg protein on brain tryptophan availability
}

\author{
E. Siobhan Mitchell ${ }^{1 *}$, Marieke Slettenaar ${ }^{1}$, Frits Quadt $^{1}$, Timo Giesbrecht ${ }^{1}$, Joris Kloek $^{2}$, \\ Cindy Gerhardt ${ }^{2}$, Arjen Bot ${ }^{1}$, Ans Eilander ${ }^{1}$ and Sheila Wiseman ${ }^{1}$ \\ ${ }^{1}$ Unilever R\&D, Olivier van Noortlaan 120, 3133 AT Vlaardingen, The Netherlands \\ ${ }^{2}$ DSM Food Specialties B.V., Delft, The Netherlands
}

(Received 22 April 2010 - Revised 16 August 2010 - Accepted 15 September 2010)

\begin{abstract}
Serotonin synthesis critically depends on plasma levels of tryptophan (TRP). Earlier studies have shown that for mood and cognitive benefits to occur, the ratio between TRP and other large neutral amino acids (LNAA) has to be increased by approximately $40 \%$. The present study investigated the dose-dependent effects of a TRP-rich hydrolysed protein (egg-protein hydrolysate, EPH) on the plasma TRP:LNAA. Moreover, it was investigated whether EPH could increase TRP:LNAA in the presence of $2 \mathrm{~g}$ of milk protein (MP). In a randomised doubleblind crossover design, plasma amino acids were measured every $30 \mathrm{~min}$ for $3.5 \mathrm{~h}$ after ingestion of a drink containing either three different doses of 4, 8 and $12 \mathrm{~g}$ EPH containing 270, 560 or $800 \mathrm{mg}$ of TRP, respectively, the combination of $4 \mathrm{~g}$ EPH and $2 \mathrm{~g}$ MP (74 mg TRP), or $4 \mathrm{~g}$ MP (148 mg TRP) in twenty healthy subjects with a mean age of 52 years. All three EPH doses caused significant increases of TRP:LNAA above $40 \%$ at 30, 60 and $90 \mathrm{~min}$ after consumption in a dose-dependent manner. Compared with the $4 \mathrm{~g}$ EPH, the increase in TRP:LNAA in the $4 \mathrm{~g}$ EPH with $2 \mathrm{~g}$ MP condition was significantly lower at $60 \mathrm{~min}(63 \mathrm{v} .44 \%, P<0 \cdot 001)$ and did not differ significantly at $90 \mathrm{~min}$ ( $58 v .53 \%, P>0.05$ ). The present study showed that a low dose of $4 \mathrm{~g}$ EPH with even the addition of $2 \mathrm{~g}$ MP was sufficient to increase the ratio of TRP:LNAA above $40 \%$. Thus, EPH offers a viable ingredient to increase TRP availability.
\end{abstract}

Key words: Large neutral amino acids: L-Type transporter: Egg protein: Milk protein: Bioavailability: Pharmacokinetics: Serotonin

Serotonin (5-hydroxytryptamine) has been implicated not only in the regulation of emotion, attention and memory but also in appetite and sleep ${ }^{(1-3)}$. Synthesis of serotonin critically depends on the availability of its precursor essential amino acid tryptophan (TRP) in the brain. Increasing brain serotonin via dietary interventions such as TRP supplementation may therefore result in cognitive and mood benefits $^{(4,5)}$.

TRP enters the brain via the L-type amino acid transporter. However, TRP competes with other large neutral amino acids (LNAA; i.e. valine, tyrosine, phenylalanine, leucine and isoleucine) for the L-type amino acid transporter ${ }^{(6)}$. Therefore, an increase in the plasma ratio of TRP over LNAA (i.e. TRP:LNAA) will facilitate the entry of TRP into the brain, more than increasing TRP levels per se. Although there is little conclusive data on how much TRP:LNAA must be increased before observing changes in memory, attention, mood or other types of behaviour in healthy adults, generally the higher the increase in TRP:LNAA from the baseline, the more likely a report of a significant finding on a cognitive task. In a substantive review of TRP supplementation studies, Silber \& Schmitt $^{(1)}$ observed that elevations of TRP:LNAA between 40 and $150 \%$ above baseline were more likely to demonstrate changes in cognition such as attention, mood and memory. Increases in TRP:LNAA of $40 \%$ above baseline are therefore thought to be minimally necessary to result in meaningful cognitive benefits ${ }^{(1,3,7-11)}$. However, more TRP supplementation studies using a range of doses need to be conducted in order to ascertain how progressive rises in TRP:LNAA modulate cognition.

Since the TRP content of most proteins is low, ingesting protein usually does not lead to an increased ratio of TRP:LNAA, or increased serotonin synthesis in the brain; however, some proteins do have a high TRP content and a favourable TRP:LNAA ratio ${ }^{(12)}$. Indeed, the consumption of TRP-rich $\alpha$-lactalbumin (ALAC), a whey-derived protein with a high TRP content, yielded promising behavioural effects with $50-130 \%$ increases in plasma TRP:LNAA ${ }^{(2)}$.

Abbreviations: ALAC, $\alpha$-lactalbumin; EPH, egg-protein hydrolysate; LNAA, large neutral amino acids; MP, milk protein; SMP, skimmed milk powder; TRP, tryptophan.

*Corresponding author: E. S. Mitchell, fax +31 104605993 , email siobhan.mitchell@unilever.com 
Recently, Markus et al. ${ }^{(2)}$ investigated the effect of a proprietary egg-protein hydrolysate (EPH) as an alternative to intact ALAC on the plasma TRP:LNAA. The TRP:LNAA ratio of this EPH is $0 \cdot 2$, higher than that of any commercially available protein. The authors compared the effect of EPH with ALAC, pure TRP, TRP-containing synthetic dipeptides and placebo. The effects of EPH on TRP:LNAA were superior to ALAC and pure TRP, while being comparable to the TRP-containing synthetic dipeptide, serine-TRP. Thus, EPH represents a promising ingredient to increase TRP:LNAA to ratios that have been shown to yield cognitively meaningful effects.

The main objective of the present study was to investigate the pharmacokinetics of TRP and the other LNAA after different doses of EPH on the plasma TRP:LNAA. A secondary objective was to examine the influence of concurrently ingested milk protein (MP) on the plasma TRP:LNAA after a low dose of EPH. Specifically, it was investigated to what extent the EPH-induced increase in the plasma TRP:LNAA ratio would be dampened by the lower ratio of MP.

\section{Experimental methods}

\section{Subjects}

Recruitment letters were sent to 2278 volunteers living in the area of Vlaardingen, The Netherlands, to invite them to attend information meetings. From the subjects who showed interest in taking part in the study, twenty subjects (fifteen females) from the general population were selected to participate in the study. Exclusion criteria for the present study were use of medication, dieting, reported intense sporting activities ( $>10 \mathrm{~h} /$ week), use of systemic antibiotics in the period of 3 months before the study, recent blood donation (i.e. 1 month (males) or 2 months (females) before the study), extensive weight change ( $\pm 10 \%$ during a period of 6 months before the study), $\mathrm{Hb}<7.0 \mathrm{mmol} / 1$ (females) and $\mathrm{Hb}<7.5 \mathrm{mmol} / 1$ (males), intolerance or allergy for one of the test products (e.g. egg white) or for the standardised meal, smoking, excessive alcohol consumption (i.e. $>21$ units/week (females) or $>28$ units/week (males)), night shift work during the study period, pregnancy, current or past metabolic diseases, chronic gastrointestinal disorders, cardiovascular or psychiatric disease. Subjects participating in the study had to have a BMI between 20 and $30 \mathrm{~kg} / \mathrm{m}^{2}$. Since the doses of TRP were set at a particular amount and not adjusted according to individual weight, it was expedient to set a maximum and a minimum so as not to include clinically obese (BMI $\geq 30 \mathrm{~kg} / \mathrm{m}^{2}$ ) or very thin individuals in the study. Subjects were encouraged to minimise changes in lifestyle and composition of their habitual diet during the entire study period, and this was checked each measurement day by a questionnaire. In addition, the subjects were instructed to refrain from using food supplements enriched with TRP and also from food supplements claiming to affect TRP:LNAA (e.g. TRP itself, ALAC or 5-hydroxytryptophan) 1 week before intervention and throughout the entire study period.

The subjects provided signed informed consent and received a reward of $€ 250$ for participation. The study was approved by the standing medical ethical committee of the Wageningen University. The study was conducted according to the Declaration of Helsinki and the Medical Research Involving Human Subjects Act (WMO).

\section{Design and dietary manipulation}

The study had a balanced single-blind, randomised, crossover design. The subjects were divided into three cohorts with cohorts consisting of six or seven subjects. The subjects were allocated to treatment orders as defined by the Williams design (which consists of four Latin squares) to receive a drink containing one of the following five treatments:

Intervention 1: water with dissolved $12 \mathrm{~g}$ EPH (TRP: $800 \mathrm{mg}$ ) and no MP.

Intervention 2: water with dissolved $8 \mathrm{~g}$ EPH (TRP: $533 \mathrm{mg}$ ) and no MP.

Intervention 3: water with dissolved $4 \mathrm{~g}$ EPH (TRP: $267 \mathrm{mg}$ ) and $2 \mathrm{~g}$ MP (74 mg TRP).

Intervention 4: water with dissolved $4 \mathrm{~g}$ EPH (TRP: $267 \mathrm{mg}$ ) and no MP.

Intervention 5: water with no dissolved EPH (TRP: $0 \mathrm{mg}$ ) and $4 \mathrm{~g}$ MP (148 $\mathrm{mg}$ TRP).

For a full listing of each drink's ingredient components, please refer to Table 1 . EPH is a partially purified lysozyme from egg-white, which has been partially hydrolysed into peptides via enzyme digestion. Production and clinical applications of EPH have previously been reported ${ }^{(2)}$. EPH was produced by DSM Food Specialties, Delft, The Netherlands. MP refers to skimmed milk powder (SMP; purchased from Friesland Food, Meppel, The Netherlands), where $80 \%$ of the solid weight is protein, consisting primarily of casein and whey proteins. The following ingredients were used for normalising flavour and texture: sucrose (Danisco, Leiden, The Netherlands), maltodextrin (Avebe,

Table 1. Ingredients (g) of the four egg-protein hydrolysate (EPH) drinks and the skimmed milk powder (SMP) reference drink

\begin{tabular}{lccccc}
\hline & \multicolumn{5}{c}{ Treatments } \\
\cline { 2 - 7 } & $12 \mathrm{~g}$ & $8 \mathrm{~g}$ & $4 \mathrm{~g}$ & $\begin{array}{c}\text { g EPH } \\
\text { and }\end{array}$ & $4 \mathrm{~g}$ \\
& $\mathrm{EPH}$ & $\mathrm{EPH}$ & $\mathrm{EPH}$ & $2 \mathrm{~g} \mathrm{SMP}$ & $\mathrm{SMP}$ \\
\hline EPH & 12 & 8 & 4 & 4 & \\
Milk protein (SMP) & & & & 2 & 4 \\
Sucrose & 23.1 & 23.1 & 23.1 & 23.1 & 23.1 \\
Maltodextrin & 7.0 & 7.0 & 7.0 & 7.0 & 7.0 \\
Carrageenan CL110 & 0.07 & 0.07 & 0.07 & 0.07 & 0.07 \\
Sucralose & 0.105 & 0.063 & 0.035 & & \\
Strawberry flavour & 0.70 & 0.70 & 0.70 & 0.70 & 0.70 \\
\hline
\end{tabular}


Veendam, The Netherlands), carrageenan (Danisco), sucralose (Tate and Lyle, London, UK) and strawberry flavour (IFF, Hilversum, The Netherlands). All drinks were made in the Unilever Research and Development Laboratory in Vlaardingen.

Each cohort contained a full Latin square and was augmented by one or two randomly selected treatment orders from the remaining Latin square. The total duration of the study was 5 weeks, and each subject was studied $1 \mathrm{~d} /$ week for each treatment.

\section{Procedure}

The subjects were encouraged to minimise changes in lifestyle and composition of their habitual diet during the entire study period. They were instructed not to exercise more or less than what they were used to doing. The subjects who exercised intensively (more than $10 \mathrm{~h} / 1$ week) were not included in the study. Furthermore, the subjects were requested to consume the provided frozen meal and snacks the evening before the test day and to repeat the time and amount every test day to ensure the same protein and carbohydrate levels, and that everything is metabolised during the baseline measurements. They were not allowed to consume anything $8 \mathrm{~h}$ before the first baseline measurement. However, they were allowed to drink water and also during the test days and repeat this every time. Additionally, they were instructed to refrain from using food supplements enriched with TRP and also from food supplements claiming to affect TRP:LNAA ratios (e.g. TRP itself, ALAC or 5-hydroxyindoleacetic acid, a serotonin metabolite) 1 week before intervention and throughout the entire study period. Additionally at the $150 \mathrm{~min}$ time point, a fruit snack was provided and checked by a dietitian to ensure that they repeated the amount and type of fruit every test day.

The time schedule for an intervention day is presented in Table 2. On the test day, a baseline blood sample was taken on arrival between 07.00 and 08.00 hours. The subjects filled out a health and lifestyle questionnaire, which was used in order to monitor the physical health of subjects and major deviations of diet and activities. Next, the subjects received the $350 \mathrm{ml}$ drink (see Table 1 for the nutritional composition), which they were required to finish within $10 \mathrm{~min}$. Research assistants who administered the drinks were blinded to the five treatments.

Seven blood samples were taken every $30 \mathrm{~min}$ for a period of $3.5 \mathrm{~h}$ to assess TRP and LNAA concentrations in the plasma. After the sixth blood collection, the subjects consumed an apple, orange or banana. The subjects' choice from session 1 was repeated during all test days.

\section{Biochemical analyses}

Two samples from each of the five drinks were analysed via HPLC for total TRP content using a method adapted
Table 2. Description of the measurement day

\begin{tabular}{ll}
\hline$T$ (min) & Description \\
\hline$<0$ & The subjects arrived in a fasting state \\
& They completed a health and lifestyle \\
questionnaire & They were inserted with an intravenous \\
& catheter in order to facilitate continuous \\
& blood draws \\
& A baseline blood draw of 4 ml was taken \\
& The subjects consumed the randomised \\
& test drink within 10 min \\
0 (approximately & Second blood draw from the subjects \\
30 & Third blood draw from the subjects \\
60 & Fourth blood draw from the subjects \\
90 & Fifth blood draw from the subjects \\
120 & Sixth blood draw from the subjects \\
150 & They consumed a piece of fruit \\
& (apple, orange or banana) \\
180 & Seventh blood draw from the subjects \\
210 & Eighth blood draw from the subjects \\
& Intravenous catheter was taken out \\
& They received a normal meal
\end{tabular}

from Delgado-Andrade et $a l^{(14)}$. Alkaline hydrolysis was used to prepare the samples, which were run on a degassed mobile phase of acetonitrile-water $(25: 75 ; \mathrm{v} / \mathrm{v})$ containing $0 \cdot 1 \%$ of trifluoroacetic acid. TRP was detected at 280 and $240 \mathrm{~nm}$ for excitation and emission wavelengths, respectively, using an Agilent 1100 system with fluorescence. All drinks were within the expected range of calculated TRP levels as compared with total protein content.

Blood samples were collected in duplicate in $10 \mathrm{ml} \mathrm{vacu-}$ tainer tubes containing sodium heparin and centrifuged at $3000 \mathrm{~g}$ for $10 \mathrm{~min}$ at $4^{\circ} \mathrm{C}$. After centrifugation, $4 \mathrm{mg}$ sulfosalicylic acid were added per $100 \mu \mathrm{l}$ of the resulting supernatants, which was directly stored at $-80^{\circ} \mathrm{C}$ until processed. Plasma amino acid analysis was conducted with HPLC via a $2-3 \mu \mathrm{m}$ Bischof Spherisorb ODS II column. The plasma TRP ratio was calculated by dividing the plasma TRP concentration by the sum of the other LNAA, i.e. valine, isoleucine, leucine, tyrosine and phenylalanine. All amino acid ratios are presented as molar weight ratios.

\section{Statistical analysis}

Changes in TRP:LNAA were the primary outcome measure of interest in the present study with LNAA being defined as the sum of tyrosine, phenylalanine, leucine, isoleucine and valine. Statistical analysis has been performed using the Statistical Analysis Systems statistical software package (version 9.1; SAS Institute, Cary, NC, USA).

All the hypotheses were tested using a mixed-model ANCOVA using subjects as the random effect and all other effects as fixed. This analysis is equivalent to a repeated-measures analysis, but takes into account that the subjects are a random selection of the population. The within-subject variability is used as the error term for 
Table 3. Plasma amino acid concentrations ( $\mu \mathrm{m} / \mathrm{l}$ ) across time ( $\mathrm{min})$ after the intake of 12,8 and $4 \mathrm{~g}$ egg-protein hydrolysate (EPH), $4 \mathrm{~g}$ EPH in combination with $2 \mathrm{~g}$ skimmed milk powder (SMP) and $4 \mathrm{~g}$ SMP

(Mean values with their standard errors)

\begin{tabular}{|c|c|c|c|c|c|c|c|c|c|c|c|c|c|c|c|c|}
\hline \multirow[b]{2}{*}{ Condition } & \multicolumn{2}{|c|}{$0 \mathrm{~min}$} & \multicolumn{2}{|c|}{$30 \mathrm{~min}$} & \multicolumn{2}{|c|}{$60 \mathrm{~min}$} & \multicolumn{2}{|c|}{$90 \mathrm{~min}$} & \multicolumn{2}{|c|}{$120 \mathrm{~min}$} & \multicolumn{2}{|c|}{$150 \mathrm{~min}$} & \multicolumn{2}{|c|}{$180 \mathrm{~min}$} & \multicolumn{2}{|c|}{$210 \mathrm{~min}$} \\
\hline & Mean & SE & Mean & SE & Mean & SE & Mean & SE & Mean & SE & Mean & SE & Mean & SE & Mean & SE \\
\hline \multicolumn{17}{|l|}{ Ile } \\
\hline $4 \mathrm{~g} \mathrm{EPH}+2 \mathrm{~g}$ SMP & 59.8 & 3.8 & 87.4 & 3.1 & 68.7 & $2 \cdot 8$ & $54 \cdot 3$ & $2 \cdot 8$ & 48.6 & $2 \cdot 4$ & $49 \cdot 6$ & $2 \cdot 1$ & $51 \cdot 7$ & 1.9 & 48.9 & 1.9 \\
\hline $4 \mathrm{~g} \mathrm{EPH}$ & $54 \cdot 6$ & $2 \cdot 6$ & $72 \cdot 8$ & $2 \cdot 4$ & 55.5 & 2.5 & $46 \cdot 1$ & $2 \cdot 3$ & $44 \cdot 3$ & $2 \cdot 1$ & $47 \cdot 3$ & $2 \cdot 0$ & $49 \cdot 8$ & 1.7 & 47.5 & 1.8 \\
\hline $4 \mathrm{~g} \mathrm{SMP}$ & 58.0 & 3.0 & $77 \cdot 0$ & 3.5 & $62 \cdot 7$ & $2 \cdot 3$ & $52 \cdot 6$ & $2 \cdot 4$ & $47 \cdot 0$ & $2 \cdot 2$ & $46 \cdot 8$ & 1.8 & $50 \cdot 0$ & 1.7 & $47 \cdot 2$ & 1.9 \\
\hline $12 \mathrm{~g} \mathrm{EPH}$ & $57 \cdot 7$ & $2 \cdot 7$ & $107 \cdot 4$ & 4.0 & 93.6 & 3.4 & $67 \cdot 2$ & 3.4 & $56 \cdot 4$ & $2 \cdot 9$ & $54 \cdot 2$ & 2.5 & $56 \cdot 0$ & $2 \cdot 0$ & $50 \cdot 4$ & $2 \cdot 0$ \\
\hline $8 \mathrm{~g} \mathrm{EPH}$ & $59 \cdot 7$ & 4.4 & $88 \cdot 3$ & 4.4 & $72 \cdot 0$ & 3.6 & $56 \cdot 4$ & $3 \cdot 1$ & $49 \cdot 8$ & $2 \cdot 7$ & $49 \cdot 8$ & 2.5 & $52 \cdot 4$ & $2 \cdot 2$ & $49 \cdot 0$ & $2 \cdot 1$ \\
\hline \multicolumn{17}{|l|}{ Leu } \\
\hline $4 \mathrm{~g} \mathrm{EPH}+2 \mathrm{~g} \mathrm{SMP}$ & $112 \cdot 9$ & 4.7 & 158.8 & 4.3 & $123 \cdot 6$ & 3.9 & $98 \cdot 3$ & 3.9 & 90.9 & 3.3 & $93 \cdot 7$ & 3.1 & 98.9 & $3 \cdot 1$ & $93 \cdot 6$ & 2.9 \\
\hline $4 \mathrm{~g} \mathrm{EPH}$ & $108 \cdot 8$ & 5.5 & $130 \cdot 6$ & 3.6 & $100 \cdot 6$ & 3.8 & 85.4 & 3.5 & 83.7 & $3 \cdot 3$ & $90 \cdot 4$ & $3 \cdot 1$ & $96 \cdot 4$ & $2 \cdot 8$ & 92.4 & 3.0 \\
\hline $4 \mathrm{~g}$ SMP & $112 \cdot 4$ & $5 \cdot 8$ & $148 \cdot 0$ & $6 \cdot 4$ & 122.4 & 4.6 & 103.9 & $4 \cdot 6$ & 94.3 & $4 \cdot 1$ & 94.5 & 3.4 & $100 \cdot 9$ & 3.5 & $95 \cdot 5$ & 3.9 \\
\hline $12 \mathrm{~g} \mathrm{EPH}$ & $112 \cdot 0$ & $4 \cdot 2$ & $187 \cdot 1$ & $6 \cdot 6$ & $153 \cdot 6$ & $5 \cdot 0$ & $112 \cdot 0$ & $5 \cdot 1$ & $96 \cdot 8$ & 4.4 & $95 \cdot 7$ & 3.7 & $101 \cdot 3$ & $3 \cdot 1$ & $92 \cdot 8$ & $3 \cdot 3$ \\
\hline $8 \mathrm{~g} E P H$ & 107.5 & 5.5 & $156 \cdot 3$ & 6.9 & $124 \cdot 7$ & 5.4 & $99 \cdot 3$ & 4.6 & $90 \cdot 2$ & 4.1 & 92.2 & 3.8 & 98.9 & 3.6 & $93 \cdot 2$ & 3.8 \\
\hline \multicolumn{17}{|l|}{ Phe } \\
\hline $4 \mathrm{~g} \mathrm{EPH}+2 \mathrm{~g}$ SMP & 64.5 & 1.4 & 73.7 & 1.5 & 65.7 & 1.4 & $59 \cdot 8$ & $1 \cdot 3$ & $56 \cdot 6$ & 1.1 & $56 \cdot 0$ & 1.3 & $56 \cdot 9$ & $1 \cdot 3$ & $56 \cdot 1$ & 1.3 \\
\hline $4 \mathrm{~g} \mathrm{EPH}$ & 61.4 & 1.6 & $65 \cdot 8$ & 1.4 & $60 \cdot 2$ & 1.6 & 54.6 & 1.7 & $52 \cdot 9$ & 1.7 & 54.9 & 1.7 & $56 \cdot 0$ & 1.6 & $55 \cdot 7$ & 1.7 \\
\hline $4 \mathrm{~g}$ SMP & $63 \cdot 6$ & 1.8 & $70 \cdot 7$ & $2 \cdot 2$ & 66.0 & 1.9 & $63 \cdot 2$ & $2 \cdot 4$ & 57.4 & 1.8 & $56 \cdot 7$ & $2 \cdot 0$ & $57 \cdot 4$ & 1.9 & $56 \cdot 5$ & 1.8 \\
\hline $12 \mathrm{~g} \mathrm{EPH}$ & $63 \cdot 1$ & $1 \cdot 7$ & $77 \cdot 7$ & $2 \cdot 0$ & 69.9 & $2 \cdot 0$ & $59 \cdot 2$ & $2 \cdot 0$ & 53.8 & 1.7 & $53 \cdot 1$ & $1 \cdot 8$ & $53 \cdot 8$ & 1.5 & $53 \cdot 3$ & 1.8 \\
\hline $8 \mathrm{~g} \mathrm{EPH}$ & $62 \cdot 2$ & 1.7 & $70 \cdot 1$ & $2 \cdot 4$ & 65.3 & $3 \cdot 1$ & $56 \cdot 8$ & 1.8 & $52 \cdot 6$ & 1.9 & $52 \cdot 4$ & 1.9 & $54 \cdot 0$ & 1.9 & $53 \cdot 6$ & 1.9 \\
\hline \multicolumn{17}{|l|}{ Tyr } \\
\hline $4 \mathrm{~g} \mathrm{EPH}+2 \mathrm{~g} \mathrm{SMP}$ & 65.5 & $2 \cdot 1$ & $81 \cdot 2$ & $2 \cdot 3$ & $72 \cdot 8$ & $2 \cdot 0$ & $64 \cdot 6$ & $1 \cdot 6$ & $59 \cdot 2$ & 1.5 & $57 \cdot 2$ & 1.5 & $56 \cdot 2$ & 1.6 & $53 \cdot 6$ & 1.6 \\
\hline $4 \mathrm{~g} \mathrm{EPH}$ & $62 \cdot 2$ & 1.7 & $69 \cdot 8$ & $2 \cdot 0$ & 64.0 & 2.5 & 55.4 & 1.7 & 51.6 & 1.7 & $51 \cdot 8$ & 1.7 & $52 \cdot 2$ & 1.5 & $50 \cdot 7$ & 1.4 \\
\hline $4 \mathrm{~g}$ SMP & 63.5 & $2 \cdot 7$ & 75.5 & $2 \cdot 6$ & 71.2 & $2 \cdot 6$ & 65.5 & $2 \cdot 6$ & 59.5 & $2 \cdot 3$ & $57 \cdot 0$ & $2 \cdot 2$ & 57.5 & $2 \cdot 1$ & 55.4 & $2 \cdot 1$ \\
\hline $12 \mathrm{~g} \mathrm{EPH}$ & $66 \cdot 3$ & 1.9 & $91 \cdot 1$ & $3 \cdot 1$ & 89.1 & $3 \cdot 2$ & $75 \cdot 2$ & $2 \cdot 5$ & $65 \cdot 6$ & $2 \cdot 2$ & $61 \cdot 2$ & 1.9 & $61 \cdot 0$ & 1.6 & $56 \cdot 8$ & 1.6 \\
\hline $8 \mathrm{~g}$ EPH & $73 \cdot 6$ & 8.9 & 79.7 & 3.4 & $72 \cdot 7$ & $2 \cdot 7$ & $65 \cdot 3$ & $2 \cdot 3$ & $59 \cdot 1$ & $2 \cdot 0$ & $56 \cdot 7$ & $2 \cdot 2$ & $56 \cdot 4$ & $2 \cdot 3$ & $53 \cdot 7$ & $2 \cdot 3$ \\
\hline \multicolumn{17}{|l|}{ Val } \\
\hline $4 \mathrm{~g} \mathrm{EPH}+2 \mathrm{~g} \mathrm{SMP}$ & $220 \cdot 1$ & $10 \cdot 2$ & $265 \cdot 1$ & $9 \cdot 0$ & 233.9 & 7.9 & $205 \cdot 2$ & 7.4 & $193 \cdot 8$ & $6 \cdot 9$ & $194 \cdot 8$ & 6.5 & $197 \cdot 7$ & 6.9 & 191.4 & $6 \cdot 6$ \\
\hline $4 \mathrm{~g}$ EPH & $200 \cdot 3$ & $7 \cdot 8$ & $227 \cdot 3$ & $7 \cdot 1$ & $200 \cdot 8$ & $7 \cdot 7$ & $178 \cdot 1$ & $6 \cdot 8$ & $174 \cdot 3$ & 6.9 & $179 \cdot 9$ & 6.5 & $183 \cdot 1$ & $5 \cdot 7$ & $180 \cdot 6$ & $6 \cdot 1$ \\
\hline $4 \mathrm{~g} \mathrm{SMP}$ & 211.6 & $10 \cdot 4$ & $245 \cdot 3$ & 9.5 & $225 \cdot 2$ & 8.9 & 203.0 & 8.6 & $190 \cdot 3$ & 8.3 & 188.5 & 7.4 & 194.4 & $7 \cdot 2$ & 188.8 & $7 \cdot 7$ \\
\hline $12 \mathrm{~g} \mathrm{EPH}$ & $215 \cdot 1$ & $7 \cdot 6$ & 284.4 & $9 \cdot 0$ & $269 \cdot 0$ & $7 \cdot 7$ & 222.4 & $7 \cdot 9$ & $202 \cdot 3$ & 7.9 & $199 \cdot 1$ & $7 \cdot 2$ & 203.6 & $6 \cdot 0$ & 193.7 & 6.5 \\
\hline $8 \mathrm{~g} \mathrm{EPH}$ & 204.6 & 11.1 & 253.1 & $10 \cdot 0$ & $227 \cdot 2$ & 8.6 & $198 \cdot 9$ & $8 \cdot 1$ & $187 \cdot 1$ & $7 \cdot 6$ & $187 \cdot 5$ & 7.5 & $193 \cdot 8$ & $7 \cdot 4$ & $185 \cdot 9$ & $7 \cdot 6$ \\
\hline \multicolumn{17}{|l|}{ Trp } \\
\hline $4 \mathrm{gEPH}+2 \mathrm{gSMP}$ & 44.9 & 1.7 & 73.5 & $2 \cdot 7$ & 70.1 & 2.6 & $62 \cdot 9$ & $2 \cdot 4$ & $54 \cdot 0$ & $2 \cdot 2$ & $49 \cdot 3$ & $2 \cdot 1$ & $46 \cdot 5$ & $1 \cdot 8$ & $46 \cdot 9$ & 1.7 \\
\hline $4 \mathrm{~g} E P H$ & 43.3 & 1.8 & $72 \cdot 8$ & 2.5 & 69.0 & $3 \cdot 1$ & $57 \cdot 7$ & $2 \cdot 3$ & $49 \cdot 6$ & $2 \cdot 1$ & $47 \cdot 2$ & 1.8 & $45 \cdot 3$ & 1.9 & $45 \cdot 8$ & 1.7 \\
\hline $4 \mathrm{~g}$ SMP & 44.9 & 1.9 & $47 \cdot 6$ & 1.7 & $45 \cdot 8$ & 1.8 & $42 \cdot 8$ & 1.7 & 39.2 & 1.6 & $38 \cdot 3$ & 1.5 & $38 \cdot 3$ & 1.5 & $40 \cdot 1$ & 1.5 \\
\hline $12 \mathrm{~g} \mathrm{EPH}$ & $45 \cdot 1$ & 1.7 & $123 \cdot 4$ & $5 \cdot 3$ & 132.9 & $6 \cdot 0$ & $107 \cdot 1$ & $4 \cdot 3$ & $86 \cdot 4$ & 3.9 & 72.5 & 3.0 & $65 \cdot 2$ & $2 \cdot 4$ & $62 \cdot 3$ & $2 \cdot 4$ \\
\hline $8 \mathrm{~g} \mathrm{EPH}$ & $43 \cdot 1$ & $3 \cdot 1$ & 94.6 & 4.9 & 95.5 & 3.7 & 83.0 & 3.9 & 68.5 & 3.6 & $61 \cdot 3$ & 3.0 & 54.9 & $2 \cdot 7$ & $53 \cdot 6$ & 2.5 \\
\hline
\end{tabular}


significance testing. As the baseline plasma TRP and LNAA levels may have had an effect on the further uptake of these components, baseline values were entered as a covariate.

Three different primary analyses were carried out: (1) the analysis of a linear dose-response relationship between the doses of Pep2Balance and the response, the ratio of blood TRP concentration over blood LNAA concentration; (2) the effect of the addition of $2 \mathrm{~g}$ MP on the $4 \mathrm{~g}$ Pep2Balance; (3) the difference between $4 \mathrm{~g}$ Pep2Balance and $4 \mathrm{~g} \mathrm{MP}$ as a peptide $v$. protein source.

The dose-response relationship analysis used only the interventions without MP, i.e. containing 4,8 or $12 \mathrm{~g}$
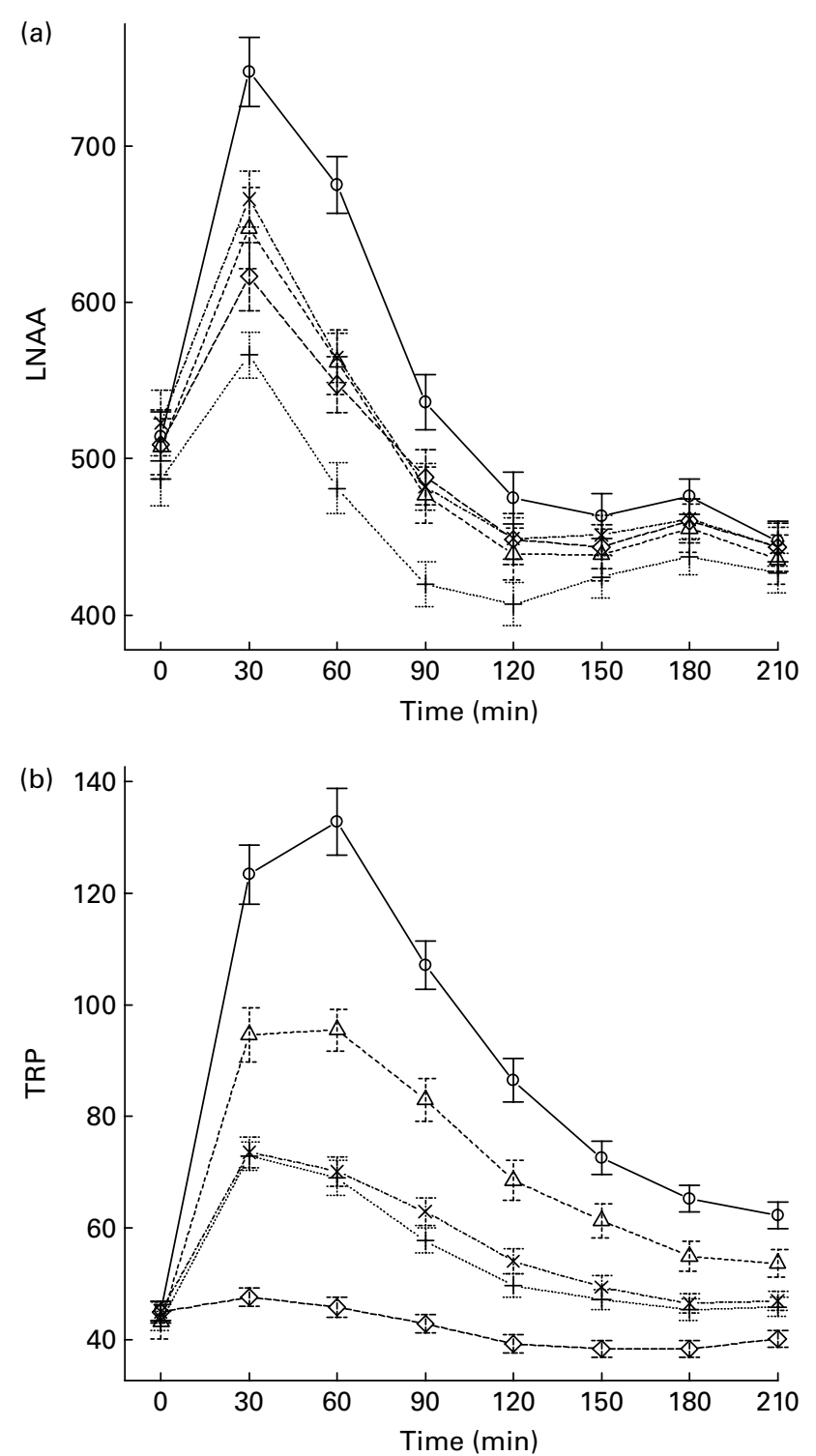

Fig. 1. (a) Mean changes in plasma large neutral amino acids (LNAA) after the intake of 12 , 8 and $4 \mathrm{~g}$ egg-protein hydrolysate $(\mathrm{EPH}), 4 \mathrm{~g} \mathrm{EPH}$ in combination with $2 \mathrm{~g}$ SMP and $4 \mathrm{~g}$ skimmed milk powder (SMP) only. (b) Mean changes in plasma tryptophan (TRP) after the intake of 12,8 and $4 \mathrm{~g} \mathrm{EPH}$, $4 \mathrm{~g} \mathrm{EPH}$ in combination with $2 \mathrm{~g} \mathrm{SMP}$ and $4 \mathrm{~g}$ SMP only. Values are means, with standard errors represented by vertical bars. $-\mathrm{O}-, 12 \mathrm{~g} \mathrm{EPH} ;-\Delta-$, $8 \mathrm{~g} \mathrm{EPH} ;-+-$, $4 \mathrm{~g} \mathrm{EPH} ;->-, 4 \mathrm{~g} \mathrm{EPH}+\mathrm{SMP} ;-\diamond-, 4 \mathrm{~g} \mathrm{SMP.}$

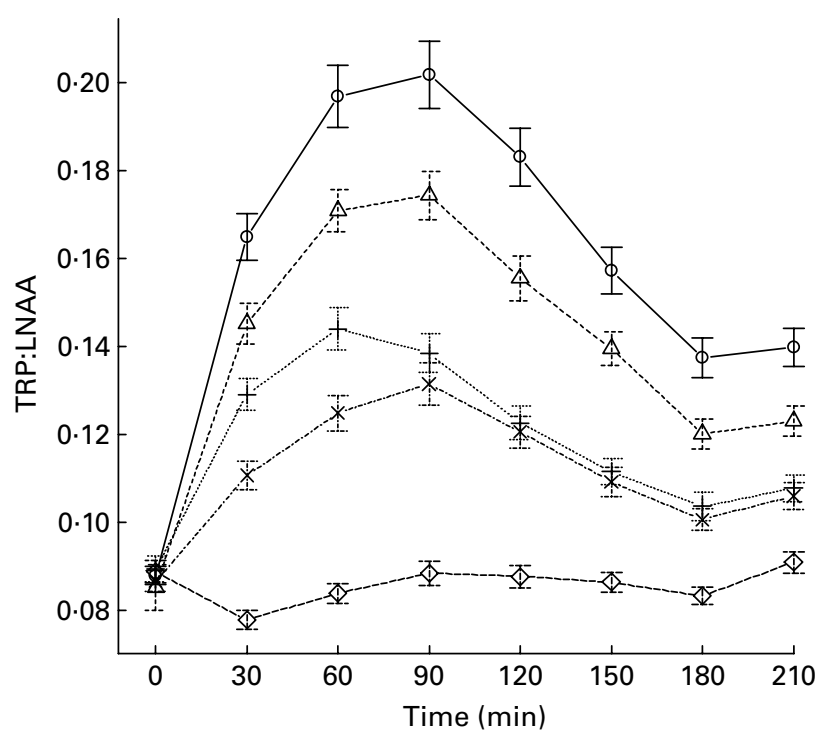

Fig. 2. Mean changes in plasma tryptophan (TRP) compared with other large neutral amino acids (LNAA) (i.e. TRP:LNAA ratio) after the intake of 12, 8 and $4 \mathrm{~g}$ egg-protein hydrolysate $(\mathrm{EPH}), 4 \mathrm{~g} E P H$ in combination with $2 \mathrm{~g}$ skimmed milk powder (SMP) and $4 \mathrm{~g}$ SMP only. Values are means, with standard errors represented by vertical bars. -O-, $12 \mathrm{~g} \mathrm{EPH} ;-\Delta-$, $8 \mathrm{~g} \mathrm{EPH} ;-+-, 4 \mathrm{~g} \mathrm{EPH} ;-\times-, 4 \mathrm{~g} \mathrm{EPH}+\mathrm{SMP} ;-\diamond-, 4 \mathrm{~g} \mathrm{SMP}$.

Pep2Balance. The regression-type analysis used the three doses of TRP, LNAA and their ratio as the independent variable and the measured blood concentration of TRP, LNAA and their ratio as the response variable. Also, covariates are used in this analysis, i.e. baseline concentration, sex, age and weight. Only the covariates that had a significant contribution were kept in the final model. The analysis resulted in an intercept and slope for each time point. The statistical analysis focuses on the latter and tests whether a linear or quadratic dose-response curve is appropriate. In the Results section the intercepts and slopes are given for TRP, LNAA and their ratio for time points 30, 60 and $90 \mathrm{~min}$, together with the probability of the intercept or slope being zero. If the probability for the slope is less than 0.05 , then the linear dose-response is statistically significant.

\section{Results}

Of the twenty subjects recruited for the study, nineteen completed all the five sessions; during the blind review, one subject was excluded from the statistical analysis. Their mean age was 52.1 (SE 10.6) years. The subjects either had a normal BMI or were overweight, with a mean BMI of $24 \cdot 1$ (SE 2.27) kg/m². No major changes in dietary habit exercise and lifestyle were reported by any of the subjects over the different phases of the study according to the analysis of the weekly questionnaires.

The mean body weight did not differ significantly between the condition the values being 72.06 ( $\operatorname{se~8.86),~}$ 71.87 (SE 8.78), 72.05 (SE 8.65), 72.10 (SE 8.83) and 71.97 (SE 9.30) $\mathrm{kg}$ for the measurement preceding the 
administration of $4 \mathrm{~g}$ EPH $+2 \mathrm{~g}$ SMP, $4 \mathrm{~g}$ EPH, $4 \mathrm{~g} \mathrm{SMP}, 12 \mathrm{~g}$ $\mathrm{EPH}$ and $8 \mathrm{~g} \mathrm{EPH}$, respectively, $(F(4,16)=0 \cdot 70, P>0 \cdot 05)$.

The mean, baseline-corrected values for all amino acids analysed are presented in Table 3. Plotting of LNAA for all doses (Fig. 1(a)) demonstrated a collective peak, which was steeper and faster than TRP (Fig. 1(b)). For example, at the $12 \mathrm{~g}$ EPH dose, TRP levels did not peak until $60 \mathrm{~min}$, while LNAA peaked at the $30 \mathrm{~min}$ time point. Mean TRP:LNAA for all treatments at all measurement points are shown in Fig. 2. The analysis of TRP:LNAA against baseline indicated a significant main effect of the treatment at all time points $(30 \mathrm{~min}: F(4,59)=190 \cdot 19$, $P<0.001 ; \quad 60 \mathrm{~min}: \quad F(4,59)=245.05, \quad P<0.001 ; 90 \mathrm{~min}$ : $F(4,59)=249 \cdot 62, \quad P<0 \cdot 001 ; \quad 120 \mathrm{~min}: \quad F(4,59)=209 \cdot 83$, $P<0.001 ; 180 \mathrm{~min}: \quad F(4,59)=115.48, \quad P<0.001 ; 210 \mathrm{~min}$ : $F(4,59)=121 \cdot 32, P<0 \cdot 001)$, indicating that the treatments affected TRP:LNAA.

The follow-up analyses indicated that all EPH doses (4, 8, 12 and $4+2 \mathrm{~g}$ SMP) caused significant increases of TRP:LNAA at all time points as compared with the reference drink containing $4 \mathrm{~g}$ SMP (all $t(58)>5.97$, all $P<0.001)$. All four treatments exceeded the threshold of at least $50 \%$ increase in TRP:LNAA at $90 \mathrm{~min}$ and all EPHonly treatments also exceeded this threshold at $60 \mathrm{~min}$. Compared with the $4 \mathrm{~g}$ EPH treatment, the addition of $2 \mathrm{~g}$ SMP resulted in slight but significantly lower TRP:LNAA 30 and $60 \mathrm{~min}$ (30 min: $t(58)=4.62, \quad P<0.001 ; 60 \mathrm{~min}$ : $t(58)=4 \cdot 15, P<0 \cdot 001)$, but not $90 \mathrm{~min}$ after administration $(t(58)=1 \cdot 11, P>0 \cdot 05)$.

Next, we investigated the dose-response relationship between TRP:LNAA and EPH by means of the regression analyses. This approach found a linear dose-response relationship for $\mathrm{EPH}$ at 120 and $150 \mathrm{~min}$ (120 min: $B=0.009, \quad$ SE $=0.003, \quad t(39)=2.69, \quad P<0.05 ; \quad 150 \mathrm{~min}$ : $B=0.010$, sE $=0.003, t(39)=3.39, P<0.05)$, with trends towards a linear relationship at 60 and $90 \mathrm{~min}(60 \mathrm{~min}$ : $B=0.007, \quad$ SE $=0.003, \quad t(39)=2.01, \quad P=0.05 ; \quad 90 \mathrm{~min}$ : $B=0 \cdot 011, \mathrm{SE}=0 \cdot 004, t(38)=2 \cdot 96, P=0 \cdot 05)$.

\section{Discussion}

The main findings of the present study can be summarised as follows. First, even low doses of EPH were sufficient to result in a peak increase of $40 \%$ or more with respect to the baseline TRP:LNAA. Previous research has suggested that substantial increases are necessary to achieve cognitive or mood effects from TRP supplementation ${ }^{(1,3,8,11,14,15)}$. Second, it was demonstrated that small amounts of SMP (i.e. $2 \mathrm{~g}$ ) only slightly compromise the increases in TRP:LNAA from moderate doses of EPH. Thus, EPH appears to be relatively resistant to these effects. However, due to size constraints of the study, we did not test several doses of MP on a full dose range of $\mathrm{EPH}$, nor were we able to assess how other types of protein interacted with EPH.

Previous studies have examined the TRP:LNAA produced by high-TRP food such as lactalbumin ${ }^{(3,8,14,15)}$. Yet these studies have typically used only one dose of lactalbumin and did not rigorously control for the effects of other types of protein present in the experiment and placebo treatments. However, this rigorousness of study design also makes it difficult to apply the present results to circumstances of a possible real-life use of EPH. The study was conducted under dietary restrictions (i.e. subjects were fasted and were not allowed to consume any food or drinks, except water and a piece of fruit) in order to optimise the study outcomes. This limits the applicability of the findings, and it is uncertain whether the effects of EPH on TRP:LNAA will remain similar under uncontrolled circumstances. Yet, Caballero et al. ${ }^{(16)}$ demonstrated that eating a regular meal should only exert a negligible influence on the effect of TRP supplementation $2 \mathrm{~h}$ after meal consumption on the increase in TRP:LNAA. Specifically, healthy lean and obese people received a $1673.6 \mathrm{~kJ}$ ( $400 \mathrm{kcal})$ lunch with $15 \%$ protein $(15 \mathrm{~g})$. After $2 \mathrm{~h}$, they received a $30 \mathrm{~g}$ sucrose snack along with $0,250,500$ or $1000 \mathrm{mg}$ of TRP. These authors reported an approximately $100 \%$ rise in TRP:LNAA as the result of ingestion of $250 \mathrm{mg}$ of TRP, which is highly comparable with our EPH $4 \mathrm{~g}$ condition. Thus, one would expect that the present findings should readily generalise to more use in daily life.

Given the hydrolysate nature of $\mathrm{EPH}$, there was a possibility that the dipeptides and tripeptides would cause TRP and other amino acids to cross through the gastrointestinal wall at a faster rate than whole proteins. However, this does not appear to be the case, since amino acids from the $4 \mathrm{~g}$ SMP were detected in the bloodstream at the same time as amino acids from $4 \mathrm{~g} \mathrm{EPH.}$ However, it may be possible with smaller time intervals of blood collection to discern a difference in rates. We were also interested in knowing whether the absorption and excretion rates of high-dose $v$. low-dose TRP would have different pharmacokinetic profiles; however, the dose-response of the EPH on TRP blood levels was found to be linear. Thus, it appears that the body does not employ alternative sequestration or metabolism routes, which alters the rate of disappearance from the blood with oral doses of TRP below $800 \mathrm{mg}$.

In summary, the present study showed that all doses of EPH were sufficient to increase the plasma TRP:LNAA ratio by $40 \%$ or more in a dose-dependent manner. It is unknown what levels of TRP:LNAA are needed for beneficial changes in mood and cognition. Moreover, it is likely that some individuals with particular personality and genetic traits will require higher or lower TRP:LNAA increases in order to elicit behavioural changes. However, $\mathrm{EPH}$ may be useful for further investigation of the link between plasma TRP:LNAA and cognition, given its powerful effects even at moderate doses. Although the addition of $2 \mathrm{~g}$ SMP to $4 \mathrm{~g}$ EPH lowered the TRP:LNAA ratio slightly at 30 and $60 \mathrm{~min}$ as compared with $4 \mathrm{~g} \mathrm{EPH}$ only, the increase in the TRP:LNAA ratio was still comparable with that of the $4 \mathrm{~g}$ of $\mathrm{EPH}$ without SMP treatment at other 
points in time. Thus, the present study has given important clues to the plasma kinetics of the TRP:LNAA after ingestion of EPH. It is worthy of note that Markus et al. ${ }^{(2)}$ provided evidence for beneficial mood effects of EPH. Yet future studies are needed to investigate cognitive benefits associated with EPH supplementation.

\section{Acknowledgements}

We are most grateful to our colleagues from Unilever and DSM who were involved in data collection, interpretation and biochemical analyses. The study was supported by Unilever Netherlands BV. The authors declare that they have no conflicts of interest. A. E., M. S., F. Q., A. B., T. G., S. W. and E. S. M. are employees of Unilever. J. K. and C. G. are employees of DSM. All authors were involved in the design of the study and in the statistical analysis plan. F. Q. and T. G. performed the statistical analysis. ᄃ M. S. managed the study. A. B. produced the study products. S. M. and T. G. wrote the manuscript. All authors reviewed and edited the manuscript and approved the final version of the manuscript.

\section{References}

1. Silber BY \& Schmitt JA (2010) Effects of tryptophan loading on human cognition, mood, and sleep. Neurosci Biobehav Rev 34, 387-407.

2. Markus CR, Firk C, Gerhardt C, et al. (2008) Effect of different tryptophan sources on amino acids availability to the brain and mood in healthy volunteers. Psychopharmacology 201, 107-114.

3. Markus CR (2005) Evening intake of alpha-lactalbumin increases plasma tryptophan availability and improves morning alertness and brain measures of attention. Am J Clin Nutr 81, 1026-1033.

4. Markus CR, Panhuysen G, Tuiten A, et al. (1998) Does carbohydrate-rich, protein-poor food prevent a deterioration of mood and cognitive performance of stress-prone subjects when subjected to a stressful task? Appetite 31, 49-65.
5. Firk C \& Markus CR (2009) Mood and cortisol responses following tryptophan-rich hydrolyzed protein and acute stress in healthy subjects with high and low cognitive reactivity to depression. Clin Nutr 28, 266-271.

6. Fernstrom JD (1994) Dietary amino-acids and brain-function. J Am Diet Assoc 94, 71-77.

7. Beulens JWJ, Bindels JG, de Graaf C, et al. (2004) Alpha-lactalbumin combined with a regular diet increases plasma Trp-LNAA ratio. Physiol Behav 81, 585-593.

8. Scrutton H, Carbonnier A, Cowen PJ, et al. (2007) Effects of alpha-lactalbumin on emotional processing in healthy women. J Psychopharmacol 21, 519-524.

9. Booij L, Merens W, Markus CR, et al. (2006) Diet rich in alpha-lactalbumin improves memory in unmedicated recovered depressed patients and matched controls. J Psychopharmacol 20, 526-535.

10. Murphy SE, Longhitano C, Ayres RE, et al. (2009) The role of serotonin in nonnormative risky choice: the effects of tryptophan supplements on the "reflection effect" in healthy adult volunteers. J Cogn Neurosci 21, 1709-1719.

11. Merens W, Booij L, Markus R, et al. (2005) The effects of a diet enriched with alpha-lactalbumin on mood and cortisol response in unmedicated recovered depressed subjects and controls. BrJ Nutr 94, 415-422.

12. Choi SJ, DiSilvio B, Fernstrom MH, et al. (2009) Meal ingestion, amino acids and brain neurotransmitters: effects of dietary protein source on serotonin and catecholamine synthesis rates. Phys Behav 98, 156-162.

13. Delgado-Andrade C, Rufian-Henares JA, Jimenez-Perez S, et al. (2006) Tryptophan determination in milk-based ingredients and dried sport supplements by liquid chromatography with fluorescence detection. Food Chem 98, 580-585.

14. Markus CR (2002) Whey protein rich in alpha-lactalbumin increases the ratio of plasma tryptophan to the sum of the other large neutral amino acids and improves cognitive performance in stress-vulnerable subjects. Am J Clin Nutr $\mathbf{7 5}$, 1051-1056.

15. Scrutton H, Carbonnier A, Cowen PJ, et al. (2007) Effects of alpha-lactalbumin on emotional processing in healthy women. J Psychopharmacol 21, 519-524.

16. Caballero B, Finer N \& Wurtman RJ (1988) Plasma amino acids and insulin levels in obesity: response to carbohydrate intake and tryptophan supplements. Metabolism 37, 672-676. 